\title{
The impact of transformational leadership on individual academy performance through knowledge sharing
}

\author{
Thi Minh Thu Vu ${ }^{a^{*}}$ and Khashayar Yazdani ${ }^{\mathrm{a}}$
}

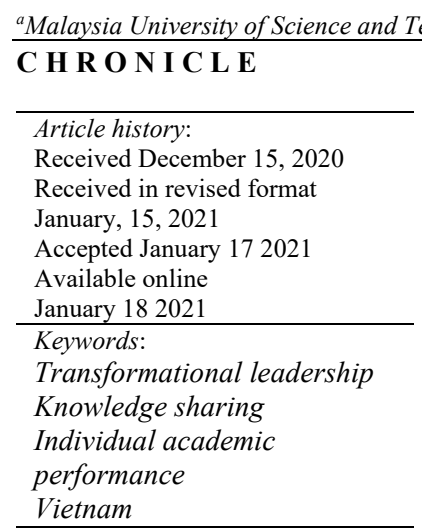

\section{A B S T R A C T}

\begin{abstract}
The objective of this paper is to evaluate the impact of transformational leadership on individual academy performance through knowledge sharing, organizational learning, organizational commitment in higher education Vietnam. The study conducts the research on 500 lecturers at 10 universities in Vietnam. The study uses Smart pls 3.6 software to analyze the data. The results show that transformational leadership had a positive effect on knowledge sharing, organizational learning and organizational commitment. Ultimately, employee engagement and social support play a moderate role in the relationship between transformational leadership and knowledge sharing statistically. However, organizational learning and organizational commitment did not play any mediate role on the relationship between transformational leadership and knowledge sharing.
\end{abstract}

(C) 2021 by the authors; license Growing Science, Canada.

\section{Introduction}

Knowledge plays an important role in the development of organizations at all levels. In economic growth models, besides physical capital, human capital is one of the central factors that determine the economic growth rate of each country (Barro, 2001; Krueger \& Lindahl, 2001). Similarly, at the micro level, knowledge is the fundamental factor, creating a competitive advantage that contributes to the sustainable development of all organizations, especially in the context of globalization and revolution 4.0 (Bock et al., 2005; Cabrera et al., 2006; Dixon, 2000; Foss et al., 2010; Ghobadi, 2015; Ipe, 2003; Parke et al., 2014; Wang \& Noe, 2010). Ipe (2003) identified knowledge as a strategic resource in organizations, determining the success of the organization. Knowledge is the foundation of the competitive advantage of all organizations (Bock et al., 2005). Accordingly, building an effective knowledge-sharing mechanism is essential for the development of organizations (Damodaran \& Olphert, 2000; Dixon, 2000; Parke et al., 2014; Wang \& Noe, 2010). Dixon (2000) stated that two main activities related to knowledge are knowledge creation and knowledge sharing. In order to effectively utilize the power of knowledge, organizations must understand how knowledge is created and how knowledge is shared within the organization (Dixon, 2000; Ipe, 2003). Therefore, knowledge sharing is just as important as knowledge creating. In addition to encouraging the creation of new knowledge, organizations need to focus on effectively exploiting the available information sources within their internal through knowledge sharing (Damodaran \& Olphert, 2000; Wang \& Noe, 2010). Effective knowledge sharing between employees and teams allows for the optimal exploitation of knowledge resources within the enterprise (Damodaran \& Olphert, 2000). Furthermore, effective knowledge sharing among employees within the organization contributes significantly to innovation - the basis of a competitive advantage for the organization (Jackson et al., 2006). In addition to doing well in recruiting and selecting employees with high qualifications in expertise and experience, organizations need to focus on building incentives for effective knowledge transfer and creativity (Dixon, 2000; Parke et al., 2014; Wang \& Noe, 2010).

* Corresponding author

E-mail address: vuminhthu.hem@gmail.com (T. M. T. Vu)

(C) 2021 by the authors; licensee Growing Science.

doi: $10.5267 /$ j.uscm.2021.1.004 
However, empirical studies on knowledge sharing are mainly conducted in the private sector. Because of its importance to the organization, the factors influencing knowledge sharing have become a topic of interest to many scholars (Grassmueck \& Shields, 2010; Hinds \& Pfeffer, 2003; Wang \& Noe, 2010). A review of previous studies shows that most of the empirical studies are conducted in the private sector with many different types of enterprises (Del Giudice et al., 2015; Dixon, 2000; Hansen, 2002; Jackson et al., 2006; Kwahk \& Park, 2016; Vuori \& Okkonen, 2012; Wang \& Wang, 2012). In contrast, there are not many studies on knowledge sharing and performance in public institutions, especially universities (Abdillah, 2014; Kassim et al., 2015). According to Kline and Saunders (1995) and Kassim et al. (2015), public sector organizations emphasize assigned duties, discipline, procedures and strict working rules, thus limiting creativity and knowledge sharing.

In particular, the empirical evidence on knowledge sharing activities among lecturers at universities is still very modest. This is a group of research subjects that have their own specific characteristics, both bearing the characteristics of public institutions (Kassim et al., 2015) and the mission of creating and knowledge sharing for society (Cronin \& Davenport, 2001). Besides, in practical terms, factors affecting knowledge sharing behavior among public university lecturers need to be studied in Vietnam in the current context. In particular, the impact of transformational leadership to knowledge sharing and academy performance. Similar to Manafi and Subramaniam (2015) in the case of Malaysia, universities in Vietnam are trying to improve their position in the global rankings. One of the useful aspects of improving the status of universities is to effectively tap into the scientific research potential of faculty (Manafi \& Subramaniam, 2015). Accordingly, improving the efficiency of the knowledge-sharing mechanism among lecturers will create better scientific value, and individual academic performance will be improved. In particular, transformational leadership plays an important role in knowledge sharing activities (De Vries et al., 2006; Ling et al., 2009). De Vries et al. (2006) said that, in addition to motivating knowledge sharing, transformational leadership also motivates knowledge sharing through attributes related to organizational commitment and organizational learning. Knowledge sharing can take place in all team activities at all levels, formal or informal in universities.

The scope of this study is limited to: only two factors affecting individual academic performance (transformational leadership and knowledge sharing) in universities, Vietnam.

The structure of the article outside of the introduction includes: Literature review, research methods, research results and conclusions.

\section{Literature review}

\subsection{Transformational leadership}

Recently, transformational leadership theory attracted an enormous amount of attention, emerging as one of the leading leadership theories (Mhatre \& Riggio, 2014). The theory was advanced and revised by Bass Bernard (1985). The concept of "Transformational Leadership" was first mentioned in the book "Leadership" by Burns (1978). The author defines the transformational leadership style as "the leader and their associates. supporting each other to reach the heights of morality and motivation". Transformational leadership has four dimensions: Individual consideration, idealized influence, inspirational motivation and intellectual stimulation (Bass \& Avolio, 1990; Judge \& Piccolo, 2004).

A transformational leader who inspires and allows for positive change at every level, from personal to organizational; knows how to seize opportunities, convert emotions, values, ethics, and long-term goals of individuals to take the business further. When properly applied, subordinates will be transformed by their leaders to increase motivation, morale and performance, through a variety of mechanisms, including uniting the consciousness and subordinates themselves. with the mission, together with the collective of the organization. The clever digital transformation understands the strengths and weaknesses of the subordinates, to arrange the right tasks for them.

Transforming leadership can appear at any level of an organization: groups, departments, divisions, or the entire organization. Such leaders are visionaries, inspirational, daring, adventurous, and thoughtful. Set in today's fiercely competitive market, transformational leadership is considered one of the most popular and effective corporate leadership styles.

\subsection{Knowleadge sharing}

In the organization, knowledge is considered one of the important assets with two main forms of existence: hidden knowledge and present knowledge (Kothuri, 2002). However, for knowledge to be valuable and create value for the organization, it is necessary to have mutual transfer between the individuals within the organization. The process of transferring knowledge from person to person at different levels between individuals and individuals or between individuals and organizations is seen as knowledge sharing. On the other hand, Cummings (2004) argues that knowledge sharing is the information provided for individuals to work together and solve problems or the process of exchanging both hidden and existing knowledge. between individuals to create new knowledge.

Knowledge is shareable (Sharratt \& Usoro, 2003; Wang \& Noe, 2010). In general, sharing is a process of one-party giving and a receiving party, whereby resources are transferred from one side to the other. However, in sharing knowledge, resources are not lost (Sharratt \& Usoro, 2003). Accordingly, knowledge sharing does not mean that the sharer renounces 
the ownership of knowledge, but instead, this process helps to connect and share knowledge between the sharer and receiver (Ipe, 2003). Therefore, knowledge sharing is reciprocal. This process differs from information sharing, which is often unidirectional. Thus, knowledge sharing is a key component of knowledge management, related to the process by individuals in an organization sharing knowledge with other individuals (Bock et al., 2005). More specifically, Cummings (2004) defines, knowledge sharing is the fact that information is exchanged and discussed so that everyone in the organization can work together and solve specific problems, develop new ideas, publish improvements or implement policies and procedures. Knowledge sharing is the process of making knowledge re-used by individuals through knowledge exchange. Accordingly, knowledge sharing plays an important role in the sustainable development of the organization. This process creates connections between individuals and organizational cohesion through the transformation of knowledge from the individual level to general knowledge at the organizational level. Thereby, knowledge creates economic value and forms a competitive advantage for an organization (Hendriks, 1999). Cohen \& Levinthal (2000) argue that interpersonal interactions with diverse and in-depth knowledge help accelerate organizational innovation far beyond the individual's ability to create. Likewise, Boland \& Tenkasi (1995) concur and argue that the competitive advantage and product success in organizations stem from the synergistic combination of knowledgeable individuals towards general results. Von Krough, Ichijo \& Nonaka (2000) also find that knowledge sharing helps to accelerate the process of creating new knowledge and utilize them to improve personal and business performance.

Thus, knowledge sharing is a process by which individuals in the organization share knowledge, contribute to knowledge application, innovation, and ultimately organizational competitive advantage (Jackson et al., 2006; Wang \& Noe, 2010). In fact, organizations are increasingly focusing on building knowledge sharing mechanisms, viewing it as an effective competitive advantage. Along with the trend of globalization, the gap in time and space is gradually narrowed, the speed of information transmission is higher and higher, the role of knowledge sharing becomes more important.

\subsection{Individual academic performance}

Individual learning performance is educational outcomes, to the extent to which all faculty members have achieved their educational goals such as Quality of work, Quantity of work, Initiative, Cooperation with other groups, Ability to complete work on time, Ability to respond quickly to problems, Its overall performance. To measure Individual learning outcomes, we used the Keller (2012), Keller (2001) general work performance scale, which was originally designed to evaluate the performance of employees. their team leader. The scale was translated into Vietnamese by two independent people, and subsequent translations were evaluated by two independent critics who had not participated in the previous translation. Specifically, we asked participants to rate their individual learning performance in relation to five metrics, such as the quality and quantity of the work done. We instruct participants to think about the fields of study, teaching, and other job assignments when they self-evaluate their overall performance on a 5-point Likert scale. The scale has five response options from 1 (very low) to 5 (very high).

\subsection{Transformational leadership, knowledge sharing and Individual academic performance}

Transformational leadership is a process where leaders inspire their employees to perform at a level that is above expectations and capable of exceeding the employee's personal interests to achieve a common goal. organization at a high level (Bass, 1999). As a result, employees in transformative leadership can maximize their performance and increase work motivation, organizational commitment, satisfaction, trust, and work engagement with the organization. (Bono \& Judge, 2003; Podsakoff et al., 1996). Additionally, transformation leaders foster an organizational culture that motivates employees to participate in the growth of the organization (Avolio \& Yammarino, 2013). Transformational leadership encourages employees to feel empowered, which improves employee engagement (Dvir et al., 2002). Such leadership behaviors encompass four distinct aspects: inspiration, intellectual stimulation, individualization, and idealized influence (Bass, 1999).

Along with transformational leadership, many contemporary organizations have been actively interested in knowledge management to increase employee productivity and productivity through more effective knowledge capture and sharing (Argote et al., 2003). Knowledge sharing among employees has long been regarded as one of the most important "success factors" in knowledge management (Carmeli et al., 2011; Mueller, 2014). Because of this importance, many scholars have conducted empirical studies on knowledge-sharing behavior and found that the employee's intention to share knowledge can be used as an indicator of sharing behavior. sharing their practical knowledge (Chen et al., 2009a, 2009b; Lin \& Lee, 2004; Reychav \& Weisberg, 2010). Through empirical research with a sample of 278 employees, Reychav \& Weisberg (2010) determined that the employee's intention to share knowledge directly and indirectly affects the employees' behavior of sharing knowledge. Sharing knowledge is affected by transformative leadership styles and positively impacts employee performance. In universities with transformational leaders, actively promote knowledge sharing and improve the effectiveness of faculty scientific research. Therefore, transformational leadership has a positive impact on individual academic performance through Knowledge sharing.

\subsection{Moderating of Employee engagement and Social support}

Employee engagement is an emotional, cognitive and behavioral state focused on an organization's common goals (Shuck \& Wollard, 2010). Engagement describes an employee's positive attitude toward an organization (Robinson et al., 2004). Affected employees have a positive, cheerful and productive working attitude (Macey \& Schneider, 2008). 
Engagement is voluntary employee behavior (Gupta et al., 2017; Macey \& Schneider, 2008). From a behavioral perspective, engaging employees is a positive approach to the employees' tasks and jobs to help them achieve the organization's goals, mission and strategy (Bakker \& Leiter, 2010). Employee engagement helps an organization create a competitive edge because it is better for employees to be productive when they are engaged, engaged and worked more productively and for longer (Gupta \& Shaheen, 2017); dedicate yourself to performing roles in the presence of others (psychologically secure), having sufficient personal resources (psychological readiness) and doing meaningful work (mind psychological meaning). Therefore, the higher an organization that has Employee engagement, the more transformational leadership drives knowledge sharing and Individual performance and vice versa.

Social support is the help and protection of others, especially for individuals or as an exchange between at least two individuals (Shumaker \& Brownell, 1984). Social support can be tangible or intangible. Social support has four components: information, tools, emotional support, and appraisal (House, 1981). Information assistance focuses on providing information in times of stress or information transgression (House, 1981). Information support plays an important role in the problemsolving process of organizations especially universities (Cronenwett, 1985). Assessment assistance involves providing information for self-assessment and verifying the appropriateness of actions and claims of others (Kahn \& Antonucci, 1980), in the Vietnamese context, supporting due diligence. It is the regulations and circulars guiding scientific research and knowledge sharing activities. Emotional support is considered to be the most important form of social support, expressed as admiration, liking, respect and love (Cobb, 1976).

The social exchange perspective (Blau, 1964) assumes that employer-worker relations are built upon mutual support, recognition and development (Van Knippenberg \& Sleebos, 2006). Leadership support, like transition support, is incentivebased, motivating employees to share knowledge and solutions to work-related problems through direct or electronic communication. According to the theory of social exchange, social support is the actions of people in relationships (Blau, 1964).

Social support, through interaction and trust, influences knowledge sharing (Hall, 2003). Chiu et al., (2006) suggested that social support has an effect on individuals' behavior of knowledge sharing. Attached employees will exhibit different frequency of knowledge sharing based on social support at and outside of work. Thus, the more social support, the more behavioral knowledge sharing will be promoted and vice versa.

\subsection{Mediating of Organizational commitment and organizational learning}

Organizational commitment is broadly defined as "strength based on the relationship of individual closeness and individual involvement in the organization" (Mowday et al., 1982) and as a factor in creating the connection between employees and the organization (Meyer et al., 1993), furthermore helping the organization achieve success (Mowday et al., 1982). Organizational commitment is positively related to organizational performance such as job performance, and employee satisfaction (Meyer et al., 1993) and institutional revenue (Meyer et al., 1993), respectively, are inversely proportional to the proportion of people absent from the workplace. labor and directly related to the intention to stay in the organization of workers (Meyer et al., 1993).

In the world there are many studies on organizational commitment, researchers have identified organizational commitment as the source and also the results of variables related to work in one organization (Foote et al., 2005). A series of studies have shown that organizational commitment is the result of individual variables, role states and workplace variables and as predictors of frequent absence from business, job performance and revenue. Along with traceability of organizational commitment factors, previous studies have discovered the correlation range of variables such as job security, job satisfaction, and association commitment. in work as well as leadership style with organizational commitment (Yahaya \& Ebrahim, 2016). Organizational learning is a dynamic process of creating and acquiring knowledge, disseminating and sharing knowledge, and applying knowledge. Organizational learning has a positive effect on improving the performance and behavior of organizational members.

The research of Wang and Hou (2015) shows that organizational learning belongs to the field of psychology and based on behavioral theory and cognitive theory, there will be different concepts about organizational learning. Many questions have been raised: can the organization learn? How will the organization learn? (3) How is the learning of the organization related to the learning of individuals within that organization? Many relevant schools of theory have answered these questions, notably the studies of Argyris \& Schon (1978) that see organizational learning as a process of error detection and correction, Daft \& Weick (1984) that the organization functions as a system of knowledge interpretation. Meanwhile, According to Fiol and Lyles (1985, pp. 803), "organizational learning is the process of organizational change based on the development of knowledge and understanding of the organization". Argote and Miron-Spektor (2011, pp. 4) state that "although there are many different theories, most scholars agree with the definition: organizational learning is the process of changing knowledge of the organization. based on the actual experience of that organization". Organizational learning as a process helps to understand the nature of how the organization learns so that there are solutions to promote these activities of the organization and Huber (1991) defined the process. These include: acquiring knowledge, sharing information, interpreting information and organizational memory. 
In this study, we only examine the role of organizational learning in improving conceptual performance. Previous researchers (Lyles \& Salk 1997; Hansen \& Wernerfelt 1989) have shown that perceived performance can reasonably substitute for objective measures of performance and that both types of metrics are valid.

\section{Research method}

\subsection{Research sample}

Target population for an educational research is defined as the full collection of all observation units or elements who are the main subject of interest (Lohr, 2010). Because this current study is particularly focused on the higher education sector in Vietnam, the scope of this research would be limited within Vietnam's higher education, this means that the target (ideal) population would cover all lecturers who currently work in the field of higher education in Vietnam and have been involved in conducting academic research. Except for being above 18 years old, other demographic factors like gender, salary level, or educational background (e.g. master or $\mathrm{PhD}$ ) are not taken into account when recruiting the survey respondents. An only additional selection criterion is that employees must have at least one-year work experience (i.e. they have worked at the current higher education institution for at least one year in order to make sure that they have sufficient amount of time to work and interact with their leader to make accurate comments on them). In the reality of doing research, the sample is often taken from a sampled population instead of the target population, thereby a sampled population only includes "possible" elements (Lohr, 2010). In connection with this, the sampling framework associated with this sampled population, from which the survey respondents are recruited for the survey study, is the list of these ten local universities: University of Economics of Ho Chi Minh City (UEH); Foreign Trade University Ho Chi Minh city campus (FTU2); Foreign Trade University Main Campus (FTU1); Ho Chi Minh University of Technology (HUTECH); Ho Chi Minh City University of Foreign Languages and Information Technology (HUFLIT); Ton Duc Thang University; Ho Chi Minh International University (HCMIU); University of Economics and Law (UEL); Vietnam National University of Forestry (VNUF); Hoa Sen University (HSU).

The questionnaires are distributed in two forms: directly sent in paper and sent online via personal email. The total number of valid votes collected is 500 votes (invalid votes such as lack of identification information are removed, only one answer is selected for all questions).

\subsection{Research model}

The research model is as follows:

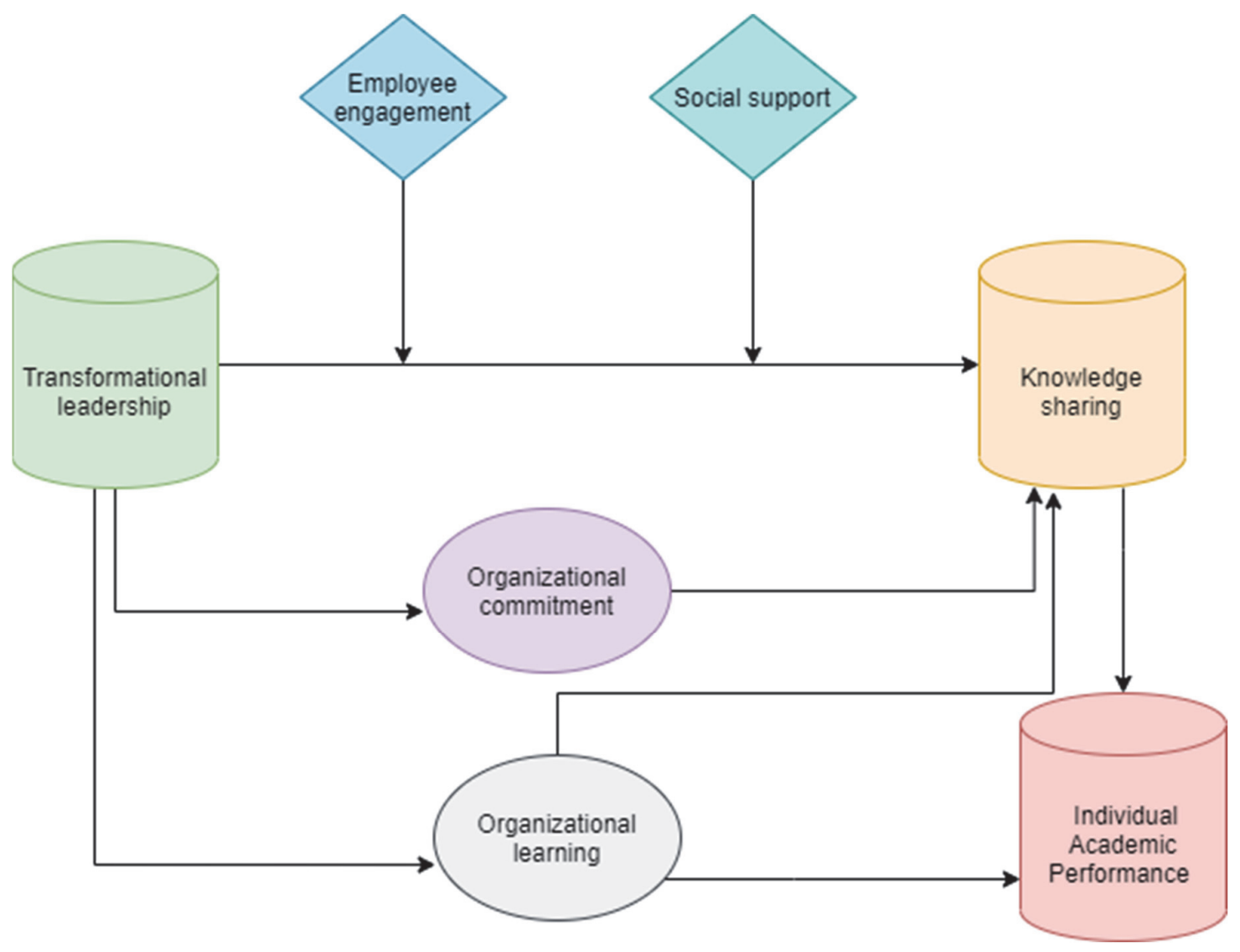

Fig. 1. Research model 
Inside:

Transformational leadership was measured by 20 items adapted from Bass's Multifactor Leadership Questionnaire (MLQ) Form 5X-Short (Bass \& Avolio, 2004); Wang et al. (2011). Each lecturer was asked to rate his or her leader's behavior on a five-point Likert scale, ranging from 1 - "not at all" to 5 - "frequently." For example, "I am proud to be associated with the leader." Four demisions were used to measure inspirational motivation, intellectual stimulation, and individualized consideration. Eight items were used to measure idealized influence.

Organizational commitment includes the six-item scale developed by Meyer et al. (1993). Among the three dimensions of organizational commitment. For example, "I would be very happy to spend the rest of my career with this organization." A five-point Liker scale was used in this study (1 strongly disagree, 5 strongly agree).

Knowledge-sharing refers to the extent that individuals share strategic knowledge with their colleagues. Five items from Bock et al. (2005), Lu et al. (2006); Phong \& Hui (2018, 2019); Zheng et al. (2017); Dari et al. (2018). A five-point Liker scale was used in this study (1 strongly disagree, 5 strongly agree).

Individual academic performance was an adapted version of the scale used by Hejazi (2006), Keller (2012), Keller (2001); Lomi et al. (2011); Ishikawa (2012); Cristine et al. (2019); Wollershein et al. (2015); Sun et al. (2014) including: Quality of work, Quantity of work, Initiative, Cooperation with other groups, Ability to complete work on time, Ability to respond quickly to problems, Its overall performance. All items were measured on a five-point Likert scale ranging from 1 (very low) to 5 (very high).

Scales for Organizational learning were newly designed through the literature review and previous empirical studies (Park \& Eun-Jee, 2018) which has 14 items. The responses used a five-point Likert scale with 1 representing "strongly disagree" and 5 representing "strongly agree".

Employee engagement was measured after the scale used by He et al. (2014) which has 11 items. For example, "I try my hardest to perform well on my job"; "I am proud of my job" and "At work, I focus a great deal of attention on my job." The responses used a five-point Likert scale with 1 representing "strongly disagree" and 5 representing "strongly agree".

Social support was developed by Akhtar et al. (2010); Oh et al. (2004). Social support scale is a 12-item scale. For example, "There is a special person who is around when I am in need"; "I have friends with whom I can share my joys and sorrows" and "My family is willing to help me make decisions." The responses were graded on a seven-point Likert scale with 1 representing "strongly disagree" and 5 representing "strongly agree".

The research hypotheses are as follows:

$\mathrm{H}_{1}$ : Transformational leadership has a positive impact on Knowledge sharing in universities in Vietnam.

$\mathrm{H}_{2}$ : Transformational leadership has a positive impact on the organizational commitment from universities in Vietnam.

$\mathrm{H}_{3}$ : Transformational leadership has a positive impact on Organizational learning in universities in Vietnam.

$\mathrm{H}_{4}$ : Organizational commitment commitment has a positive impact on Knowledge sharing in universities in Vietnam.

$\mathrm{H}_{5}$ : Organizational learning has a positive impact on Knowledge sharing in universities in Vietnam.

$\mathrm{H}_{6}$ : Organizational learning has a positive impact on the Individual academic performance in universities in Vietnam.

$\mathrm{H}_{7}$ : Knowledge sharing has a positive impact on the Individual academic performance in universities in Vietnam.

$\mathrm{H}_{8}$ : Organizational commitment and Organizational learning play an intermediate role in the relationship between Transformational leadership and Knowledge sharing.

$\mathrm{H}_{9}$ : Employee Engagement and Social support play a regulating role in the relationship between Transformational leadership and Knowledge sharing.

\subsection{Data analysis technique}

a. Evaluate the reliability of the scale with Cronbach's Alpha coefficients

First, the study uses Cronbach's Alpha coefficients to eliminate variables with low reliability of the scale because this can create dummy factors (Nguyen Dinh Tho \& Nguyen Thi Mai Trang, 2009; Nguyen Dinh Tho, 2011). Cronbach's Alpha is a method of statistically testing the degree of rigor (the ability to explain a research concept) of a set of observed variables on the scale through Cronbach's Alpha coefficients. This coefficient varies in the range [0 - 1]. 
Cronbach's Alpha coefficient is as high as possible, showing a high reliability scale (Nguyen Dinh Tho \& Nguyen Thi Mai Trang, 2009; Nguyen Dinh Tho, 2011). However, the case that Cronbach's Alpha's coefficients are too high (roughly equal to 1) is also not good because this implies that the scale variables on the scale do the same thing. Some researchers suggest that Cronbach's Alpha coefficients of 0.6 or more are usable where the concept to be measured is new, or new to the respondent in the context of the study (Hair et al.,2006). Accordingly, the statistical criteria to evaluate the scale that can be used in this study are Cronbach's Alpha coefficients must be from 0.6 or more and not too close to 1.0.

However, if only based on Cronbach's Alpha coefficients, the study will not know which variables should be eliminated, which variables should be kept to improve the reliability of the scale. Therefore, in addition to Cronbach's Alpha coefficient, the study considers the correlation coefficient of the total variable (Item - Total Correlation). Total variable correlation coefficient (Item - Total Correlation) is a coefficient that indicates the correlation of one variable with the sum of the remaining variables in the same scale. The higher the coefficient, the higher the correlation of the measure and with the rest of the same group. The total variable correlation coefficient of an observed variable should not be less than 0.3 (Hoang Trong \& Chu Nguyen Mong Ngoc, 2008).

Thus, based on the above standards, the observed variables with the total variable correlation coefficient $<0.3$ and scale components with Cronbach's Alpha coefficient outside below 0.6 or too large (almost equal to 1) are considered. is an inappropriate variable and will be removed from the scale (Hoang Trong \& Chu Nguyen Mong Ngoc, 2008).

\section{b. Exploratory Factor Analysis (EFA)}

Next, the study used Exploratory Factor Analysis (EFA) method. This method aims to answer the question of whether the observed variables (used to consider the impact of the constituent factors on knowledge sharing behavior) are highly cohesive and can they be reduced. No (Hoang Trong \& Chu Nguyen Mong Ngoc, 2008, Hair et al. 2006, 2011, 2014, 2017). In other words, exploratory factor analysis EFA is used to test and redefine groups of variables in the research model.

This method belongs to the multivariate analysis group interdependent, so the method does not distinguish the dependent variable and the independent variable but depends on the relationship between the variables. From there, the method proposes to reduce a set of $\mathrm{k}$ observed variables into a set $\mathrm{F}$ of more significant factors $(\mathrm{F}<\mathrm{k})$. In addition, the convergence and divergence values were also assessed through the EFA analysis step (Nguyen Dinh Tho, 2011).

According to Hoang Trong \& Chu Nguyen Mong Ngoc (2008) and Nguyen Dinh Tho (2011), When analyzing the test results from the EFA analysis, the indicators should be considered as follows:

+ Test KMO (Kaiser - Meyer - Olkin measure of sampling adequacy): KMO is an index used to evaluate the suitability of the method of exploratory factor analysis (EFA). This index compares the magnitude of the correlation coefficient between the two variables $\mathrm{Xi}$ and $\mathrm{Xj}$ and their partial correlation coefficient. According to Nguyen Dinh Tho (2011), with a large KMO index (from 0.5 to 1 ), the data set is considered suitable for exploratory factor analysis. This value is as close to 1 as possible because the share between variables is larger. Similarly, Hoang Trong \& Chu Nguyen Mong Ngoc (2008) explain in more detail: The value of KMO index in the range of [0,9 - 1] is very good; about [0.7-0.9] is usable and about [0.5 $0.7]$ is temporarily usable. In case $\mathrm{KMO}<0.5$, the discovery factor analysis is likely not appropriate with the data.

+ Bartlett's test (Bartlett's test of sphericity): used to test correlation matrices is the unit matrix I or not. The unit matrix I is a matrix whose components (correlation coefficient between variables) are 0 and the diagonal (correlation coefficient with itself) equals 1. If the Bartlett test method has $\mathrm{p}$ value $<5 \%$, the thesis rejects hypothesis $\mathrm{H} 0$ : Correlation matrix is the unit matrix, that is, the variables are correlated with each other in the whole (Nguyen Dinh Tho, 2011).

+ Eigenvalue criterion: the number of factors determined in the factor with the minimum eigenvalue is 1 (Hair et al., 2011).

+ Total variance Explained TVE (Total Variance Explained): this index implies that the extracted factors (factors with Eigenvalues value $\geq 1$ ) will explain how many percent of the measured variables. Accordingly, TVE must reach $50 \%$ or more to conclude that the EFA model is suitable (Hair et al., 2014).

+ Factor Loading: This coefficient shows the correlation between variables and factors. factor load factor $>0.3$ is considered to be the minimum, factor load factor $>0.4$ is considered important, factor load factor $>0.5$ is considered practical (Hair et al., 2006). The observed variables with factor load coefficients of less than 0.5 in the EFA are removed to ensure convergence among the variables. In addition, according to Nguyen Dinh Tho (2011), to ensure the discriminatory value of the scale, the difference between the factor weights of an observed variable must be $\geq 0.3$.

\section{c. Test research hypotheses}

Linear regression analysis assesses the impact of factors affecting knowledge sharing behavior. Or to say generally, regression analysis is used to test the linear relationship between the variables in the model, between the independent variables and the dependent variable. In addition, the author also considers the correlation between the independent variables to ensure that multiple collinearity does not occur and to ensure that a linear regression model can be used. Multicollinearity coefficients can be tested through the variance magnification factor (VIF), VIF $>10$, the multi-collinearity phenomenon occurs (Nguyen Dinh Tho, 2011). Adjusted R2 coefficient is the coefficient representing the variation of knowledge sharing 
behavior which is explained by observed variables to evaluate and test the model's suitability with the data set. After analyzing the correlation between variables, the study used structural equation models to test the research hypotheses using Smart PLS 3.6 software. In this case study, all variables use the same Likert scale with values from 1 to 5, so the larger the estimation coefficient, the more the independent variable, the stronger the impact on the dependent variable is.

\section{Result}

Among totally 500 valid respondents, the gender split was 219 males and 281 females, representing 43.8 percent and 56.2 percent. This means that the sample appears unbiased in terms of gender's representativeness as the percentage difference between the number of male lecturers and female counterparts is quite trivial. Accordingly, those who were between 27 and 32 years old dominated and accounted for over a half (51.2 percent) of the sample. It is followed by those who were from 18 to 26 years of age and occupied nearly a quarter (22.6 percent). Meanwhile, informants aged between 33 and 40 only contributed less than 15 percent (14.4 percent) and those who were older than 40 years old made-up just 11.8 percent. Overall, from these figures, it can be deduced that the sample is relatively young. This is because there is an ongoing structural change in the higher education sector in Vietnam as many young lecturers who graduated from abroad universities return to Vietnam to start researching and teaching at local higher education institutions.

Subsequently, 500 participants were asked about their educational background. Particularly, while only less than 10 percent (6.8 percent) said that they were only qualified with a bachelor diploma, nearly three-fifths of the sample (57.2 percent) said that they held a master's degree. Meanwhile, 29.8 percent indicated that they pursued or held a doctoral degree. The rest of 6.2 percent, who were qualified with a $\mathrm{PhD}$, revealed that they were already promoted to an associate or full professor position. Therefore, around two-fifths (40.2 percent) among total people said that they had been working at the current higher education institution for 3-5 years, followed by those who worked between 5 and 7 years (30.6 percent). Meanwhile, nearly 11 percent (10.8 percent) unveiled that they were employed by their university from 7 to 9 years and just 6.4 percent said that their work experience exceeded 9 years. Also, only 12 percent indicated that they were employed less than 3 years at the current university. Overall, sample's work experience is varied, depending on the position of the respondents, for example, a full professor would have longer work experience than a bachelor or master holder. In the final, 500 respondents were required to reveal their monthly income, whereby up to 71 percent of the sample said that they could earn between 10 and 20 million VND a month whereas around 16.6 percent told that their monthly earning surpassed 20 million VND and 12.4 percent admitted their monthly salary under 10 million VND. (Sample's Demographic Profile in Appendix). With 500 observations obtained, this sample size is completely consistent with the experimental rule (Hair et al. 2011). The author uses SPSS 23.0 software to synthesize data, perform analysis and test research hypotheses using SmartPLS 3.6 software.

The scales of observed variables all have Cronbach's Alpha coefficients greater than 0.812 and less than 0.901. In which, the total variable correlation coefficient of the observed variables reached a value greater than 0.3 . Therefore, these component measurement variables all meet the requirements and conditions for discovery factor analysis (EFA). After assessing the reliability of the scale, the observed variables were included in the EFA discovery factor analysis. As mentioned above, exploratory factor analysis EFA is a method in the group of interdependent multivariate analysis, so the method does not distinguish the dependent variable and the independent variable but is based on the relationship. between variables. Therefore, the author analyzes at the same time all observed variables measuring the factors. To evaluate the appropriateness of the method of factor analysis to discover EFA, Barlett's test needs to be performed. The test results show that the KMO coefficient is $0.835(>0.5)$, and the Bartlett test is statistically significant (Sig. $=0.000<0.05)$. Accordingly, the method of factor analysis to discover EFA is appropriate. The value of Eigenvalues stopped at $1.123>1$, the total extracted variance (TVE) was $69.856(\%)>50 \%$, indicating the suitability of the method of factor analysis EFA. Therefore, the conclusion of this factor analysis is appropriate. The results of the EFA factor analysis show that, compared to the Eigenvalues index, 7 factors are extracted (the number of factors with Eigenvalues index is greater than 1 . The number of extracted factors is 7 factors, so tissue image remains unchanged. Thus, the steps to analyze the reliability of the scale and the factor analysis for discovery EFA performed on SPSS 23 are satisfied. Next, the study tests research hypotheses using SmartPLS 3.6 software. The results of testing the reliability of the general scale are as follows:

Table 1

Construct Reliability and Validity

\begin{tabular}{lllll}
\hline & Cronbach's Alpha & rho_A & Composite Reliability & Average Variance Extracted (AVE) \\
\hline Individual Academic Performance & 0.907 & 0.949 & 0.948 & 0.645 \\
Employee engagement & 0.923 & 0.935 & 0.925 & 0.805 \\
Knowledge sharing & 0.920 & 0.921 & 0.920 & 0.696 \\
Organizational commitment & 0.838 & 0.869 & 0.842 & 0.645 \\
Organizational learning & 0.905 & 0.945 & 0.945 & 0.775 \\
Social support & 0.912 & 0.935 & 0.932 & 0.776 \\
Transformational leadership & 0.922 & 0.983 & 0.982 & 0.661 \\
\hline
\end{tabular}

Looking at the results in Table 1 shows, all the research variables satisfy the reliability of the scale with Cronbach's Alpha coefficients are greater than 0.838 and less than 0.923 and AVE coefficients are greater than 0.5. Satisfactory to perform the next test is to evaluate the discriminant validity of the research variables. 
Table 2

\begin{tabular}{|c|c|c|c|c|c|c|c|}
\hline & 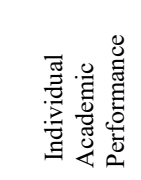 & 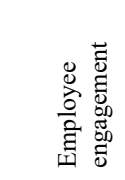 & 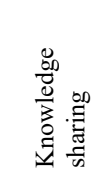 & 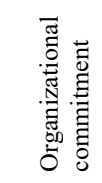 & 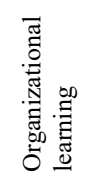 & 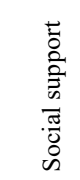 & 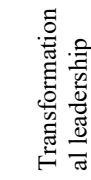 \\
\hline Individual Academic Performance & 0.803 & & & & & & \\
\hline Employee engagement & 0.418 & 0.897 & & & & & \\
\hline Knowledge sharing & 0.538 & 0.489 & 0.834 & & & & \\
\hline Organizational commitment & 0.334 & 0.244 & 0.223 & 0.803 & & & \\
\hline Organizational learning & 0.381 & 0.284 & 0.237 & 0.350 & 0.880 & & \\
\hline Social support & 0.364 & 0.597 & 0.380 & 0.232 & 0.272 & 0.881 & \\
\hline Transformational leadership & 0.335 & 0.486 & 0.466 & 0.205 & 0.181 & 0.593 & 0.813 \\
\hline
\end{tabular}

The results show that the maximum value outside the diagonal is 0.597 is also smaller than the minimum value on the diagonal of 0.803, so that means all research variables are guaranteed to have differentiation (Hair et al. 2006, 2011, 2014, 2017; Henseler et al. 2009, 2015). Next, we evaluate research model measurement values such as f-square, R-square and model fit.

Table 3

The results of R Square

\begin{tabular}{lll}
\hline & R Square & R Square Adjusted \\
\hline Individual Academic Performance & 0.358 & 0.355 \\
Knowledge sharing & 0.318 & 0.309 \\
Organizational commitment & 0.242 & 0.239 \\
Organizational learning & 0.233 & 0.230 \\
\hline
\end{tabular}

The R-square results show that all latent variables in the research model account for $35.8 \%$ of the variation of the Individual academic performance dependent variable, which is a pretty good result (Hair et al., 2014, 2017; Henseler et al. 2015). In addition, the pre-hidden variables in the research model also explain $31.8 \%$ of the variation of Knowledge sharing variables in the research model. This result shows that the research model has practical significance and statistical significance.

Table 4

Model fit

\begin{tabular}{lll}
\hline & Saturated Model & Estimated Model \\
\hline SRMR & 0.057 & 0.075 \\
d_ULS & 5.481 & 9.555 \\
d_G & 3.297 & 3.350 \\
Chi-Square & 6981.014 & 7047.681 \\
NFI & 0.891 & 0.898 \\
\hline
\end{tabular}

CB-SEM relies on several indicators to measure goodness-of-fit measures based on the difference between the covariance matrix of experimental and theoretical models. While PLS-SEM relies on variances instead of covariances to calculate the optimal solution, covariance-based goodness-of-fit model suitability indicators are not adequate in the context of PLS-SEM. Model fit indices in PLS-SEM are based on variance variance and focus on the difference between observed values (in the case of directly observed variables) or approximate values (in case of variable latent variables). (latent) of the dependent variable and the value predicted by the model. The parameters of the model show that the research data is consistent with the research model Hair et al. (2014).

Table 5

f Square

\begin{tabular}{|c|c|c|c|c|c|c|}
\hline 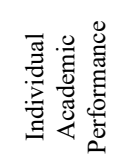 & 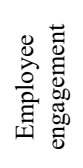 & 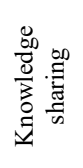 & 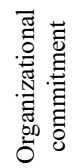 & 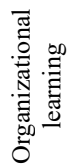 & 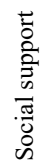 & 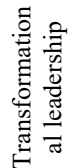 \\
\hline
\end{tabular}

\begin{tabular}{|c|c|c|c|c|}
\hline \multicolumn{5}{|c|}{ Individual Academic Performance } \\
\hline Employee engagement & & 0.201 & & \\
\hline Knowledge sharing & 0.212 & & & \\
\hline Organizational commitment & & 0.308 & & \\
\hline Organizational learning & 0.332 & 0.195 & & \\
\hline Social support & & 0.183 & & \\
\hline Transformational leadership & & 0.350 & 0.264 & 0.256 \\
\hline
\end{tabular}


$\mathrm{f} 2=\left(\mathrm{R} 2\right.$ included $-\mathrm{R} 2 \_$excluded $) /(1-\mathrm{R} 2$ included $)$

The values $f 2$ correspond to $0.02,0.15$, and 0.35 , corresponding to the small, medium and large impact values (Hair et al. 2006, 2011, 2014, 2017; Henseler et al. 2009, 2015) of exogenous variables. If the effect size is $<0.02$ then it is considered as having no effect. The results in Table 5 show that the values of $\mathrm{f} 2$ are both greater than 0.15 and less than 0.35 , which means that exogenous variables have a moderate impact on endogenous variables.

Next, we proceed to test the research hypotheses. The results extracted from Smart PLS 3.6 software using Bootstrapping technique given in Fig. 2. The results extracted from Smart PLS 3.6 are given in Fig. 3 and confirm the hypotheses.

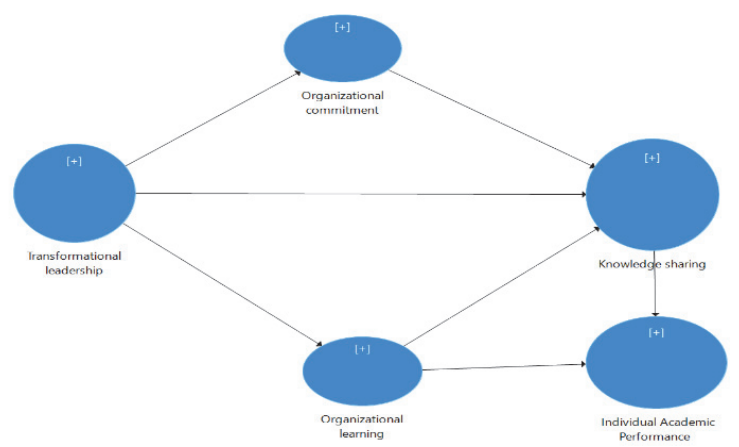

Fig. 2. The model tests independent hypotheses

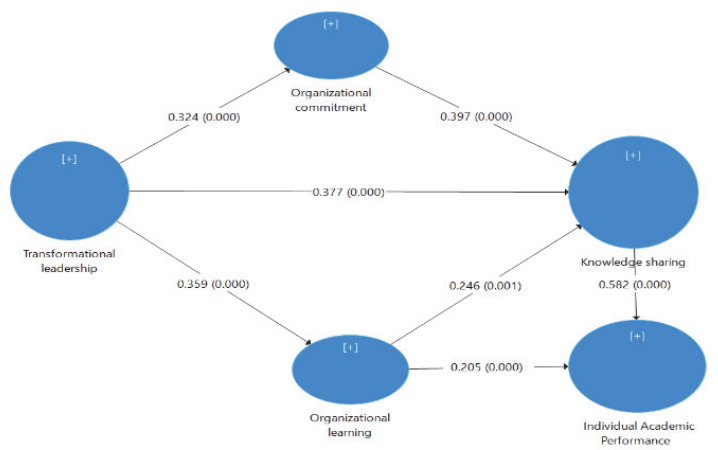

Fig. 3. The results of testing research hypotheses

Transformational leadership has a direct positive impact on the Organizational commitment with a very strong impact factor of 0.359 at a $1 \%$ significance level $\left(P_{-}\right.$value $\left.=0.000\right)$. This means that universities in Vietnam in a transformative leadership style will strongly promote Organizational learning activities. Transformational leadership has a direct positive impact on Organizational learning with a very strong impact coefficient of 0.324 at a significant level of $1 \%\left(\mathrm{P}_{-}\right.$value $\left.=0.000\right)$. This means that universities in Vietnam in a transformative leadership style will make faculty more satisfied with their work, be more active in the overall goals of the organization and lead to commitment and engagement. more permanent organization. Transformational leadership has a direct positive impact on Knowledge sharing with a very strong coefficient of 0.377 at a significant level of $1 \%\left(\mathrm{P}_{-}\right.$value $\left.=0.000\right)$. This means that the knowledge sharing activity in universities - which creates knowledge depends greatly on the leadership style of the school leaders. If the school leadership follows a transformative leadership style, it will help teachers to devote their best and share knowledge more actively and proactively. An organization, a university where knowledge sharing activities are carried out effectively, proactively and positively will have a positive impact on the efficiency and effectiveness of the organization and of the individuals in the team. (Sun et al. 2014; Keller, 2012). In this study, the Vietnamese universities also have Knowledge sharing which has a very strong direct positive impact on the individual academic performance of the faculty with an impact coefficient of up to 0.582 at a significance level of $1 \%\left(P_{-}\right.$value $\left.=0.000\right)$. At the same time, Organizational learning also has a fairly strong direct impact on the Individual academic performance of the lecturers with an impact coefficient of 0.205 at a significant level of $1 \%$ $\left(\mathrm{P}_{-}\right.$value $\left.=0.000\right)$. Next, the study tests the mediating role of two mediating variables in the research model, namely Organizational commitment and Organizational learning. In the Bootstrapping results in the overall SEM model in Figure 3, it shows that the direct relationship between Transformational leadership and Knowledge sharing is still statistically significant at a very strong level of 0.377 at a significance level of $1 \%\left(\mathrm{P}_{-}\right.$value $\left.=0.000\right)$. Therefore, according to Hair et al. (2014) two intermediate variables Organizational commitment and organizational learning do not play an intermediate role in the relationship between Transformational leadership and Knowledge sharing of faculty in universities in Vietnam. Next, we test the regulatory role of two moderator variables in the research model, namely Employee Engagement and Social support. The testing model is in Fig. 4.

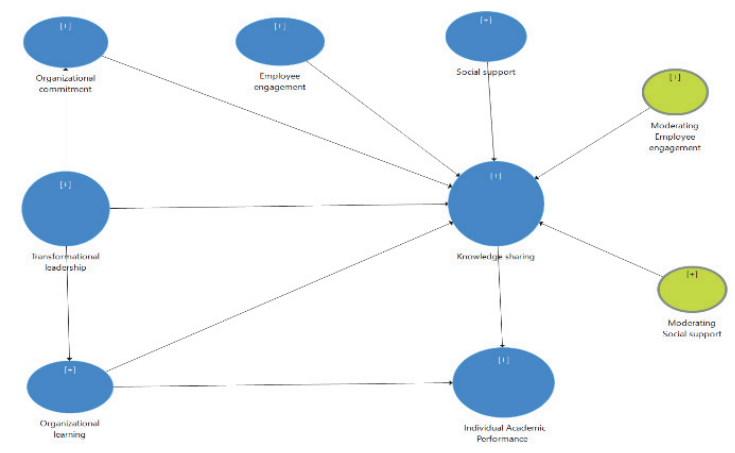

Fig. 4. Regulatory role testing model

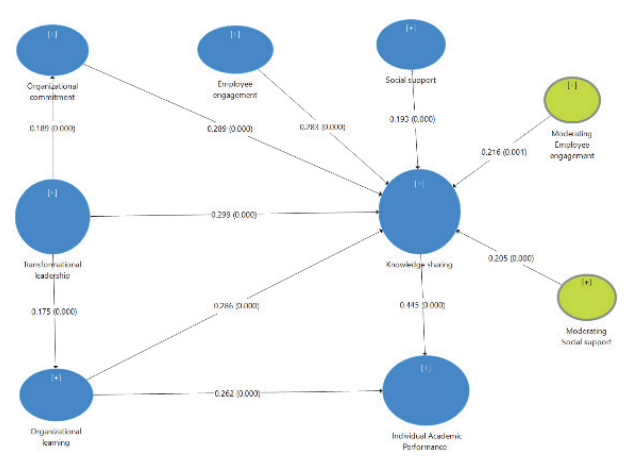

Fig. 5. The results of the regulatory role test 
When there are regulatory variables in the research model, the impact level of the research variables changes. Transformational leadership has a direct positive impact on the Organizational commitment from an impact factor of 0.189 at a $1 \%$ significance level $\left(\mathrm{P}_{-}\right.$value $\left.=0.000\right)$. Transformational leadership has a direct positive impact on Organizational learning with an impact coefficient of 0.175 at a significant level of $1 \%\left(\mathrm{P}_{-}\right.$value $\left.=0.000\right)$. Transformational leadership has a direct positive impact on Knowledge sharing with an impact factor of 0.299 at a significant level of $1 \%\left(\mathrm{P}_{-}\right.$value $\left.=0.000\right)$. Knowledge sharing has a very strong direct impact on the individual academic performance of faculty members with an impact coefficient of 0.445 at the $1 \%$ significance level $\left(\mathrm{P}_{-}\right.$value $\left.=0.000\right)$. At the same time, Organizational learning also has a fairly strong direct impact on the Individual academic performance of the lecturers with an impact coefficient of 0.262 at a significant level of $1 \%\left(\mathrm{P}_{-}\right.$value $\left.=0.000\right)$. At the same time, both Employee Engagement and Social support moderator variables have a statistically significant positive effect on Knowledge sharing with impact coefficients of 0.283 and 0.193 respectively at the significance level of $1 \%\left(\mathrm{P}_{-}\right.$value $\left.=0.000\right)$. This means that two moderator variables qualify to test the regulatory role in the relationship between Transformational leadership and Knowledge sharing. The bootstrapping results in Fig. 5 shows that the moderator variable of Employee engagement has a statistically significant effect on Knowledge sharing with an impact coefficient of $0.216\left(\mathrm{P}_{\text {_value }}=0.001\right)$ and the moderator variable of Social support also has a significant effect. statistical significance to Knowledge sharing with an impact factor of $0.205\left(P_{-}\right.$value $\left.=0.000\right)$. Table 6 summarizes the results.

Table 6

The summary of testing the hypotheses

\begin{tabular}{|c|c|c|c|c|c|}
\hline & 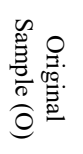 & 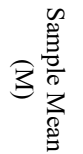 & 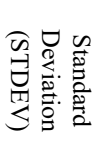 & 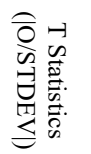 & 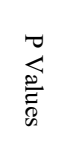 \\
\hline Employee engagement $\rightarrow$ Knowledge sharing & 0.283 & 0.277 & 0.064 & 4.423 & 0.000 \\
\hline Knowledge sharing $\rightarrow$ Individual Academic Performance & 0.445 & 0.448 & 0.040 & 11.124 & 0.000 \\
\hline Moderating Employee Engagement $\rightarrow$ Knowledge sharing & -0.015 & -0.015 & 0.057 & 5.225 & 0.000 \\
\hline Moderating Social Support $\rightarrow$ Knowledge sharing & 0.058 & 0.058 & 0.040 & 6.627 & 0.000 \\
\hline Organizational commitment $\rightarrow$ Knowledge sharing & 0.067 & 0.066 & 0.045 & 7.124 & 0.000 \\
\hline Organizational learning $\rightarrow$ Individual Academic Performance & 0.262 & 0.264 & 0.045 & 5.802 & 0.000 \\
\hline Organizational learning $\rightarrow$ Knowledge sharing & 0.079 & 0.082 & 0.052 & 7.400 & 0.000 \\
\hline Social support $\rightarrow$ Knowledge sharing & 0.017 & 0.023 & 0.070 & 3.229 & 0.000 \\
\hline Transformational leadership $\rightarrow$ Knowledge sharing & 0.299 & 0.300 & 0.069 & 4.333 & 0.000 \\
\hline Transformational leadership $\rightarrow$ Organizational commitment & 0.189 & 0.195 & 0.048 & 3.970 & 0.000 \\
\hline Transformational leadership $\rightarrow$ Organizational learning & 0.175 & 0.175 & 0.049 & 3.550 & 0.000 \\
\hline
\end{tabular}

According to Table 6, all theories are supported, except for the Organizational commitment and Organizational learning hypothesis that play a mediate role in the relationship between Transformational leadership and Knowledge sharing.

To visualize the regulatory role of Employee engagement and Social support, the study performed coefficient of impact analysis according to Hair et al. (2017) is given in Fig. 6.

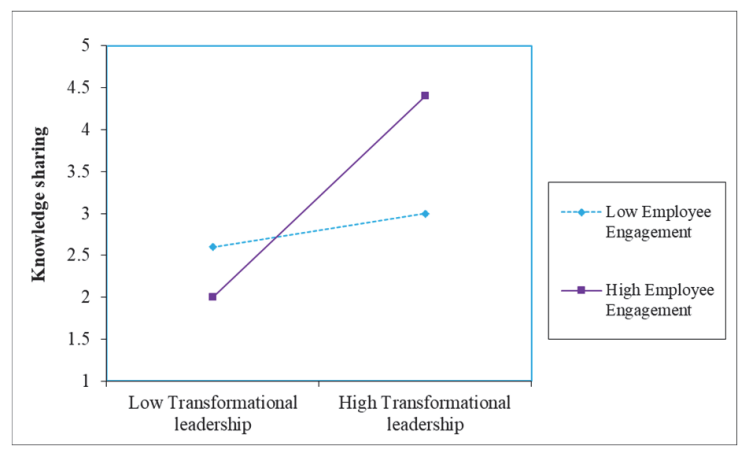

Fig. 6. The regulatory role of Employee Engagement

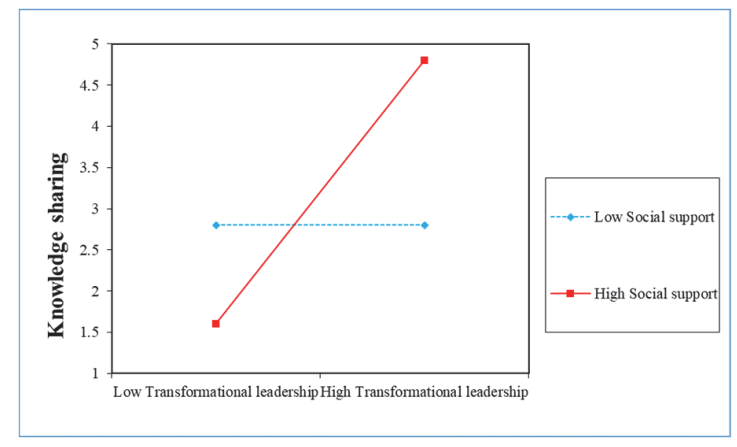

Fig. 7. Regulatory role of Social support

From the results in Fig. 6, it shows that Transformational leadership always has a positive impact on Knowledge sharing under the regulation of Employee Engagement. If in organizations - specifically universities in Vietnam, the larger Employee Engagement, the more Transformational leadership makes the more powerful impact on Knowledge sharing. This means that the more widely transformational leadership is applied, the more faculty and staff members are strongly associated with the organization with the university, and then they work with a dedicated attitude, so there will be more shared spirit and more knowledge. However, when transformational leadership is applied less, teachers will be less engaged and dedicated, but they still share their knowledge within the organization but at a lower level. From Figure 6, the low Employee engagement line has a smaller angular coefficient than the High Employee Engagement line. Finally, the 
regulatory role of Social support is given in Fig. 7. The results in Fig. 7 show that the more social support the culture of social support is carried out, the larger the social support culture will be formed. In an environment where there is a lot of information Social support and Transformational leadership are widely applied, knowledge sharing activities are done very strongly with High social support lines with a very large angle coefficient, very steep lines. However, if the universities are in a context with little social support, Transformational leadership has little impact on the Knowledge sharing of teachers. This could be explained that when there are market shocks of information asymmetry, each instructor himself does not feel secure when they share their knowledge. They may have their ideas stolen or not rewarded. Therefore, they are not confident and proactive in sharing knowledge even though leaders are encouraged.

\section{Conclusion}

From the research results of this study, in order to enhance the Individual academic performance, knowledge sharing, universities in Vietnam should apply Transformational leadership at all levels, departments, and faculties of the school. Because Transformational leadership will promote knowledge sharing, help teachers engage, engage with the organization more. At the same time, transformational leadership also helps shape the learning culture of the organization, thereby enhancing the Individual academic performance and efficiency of the organization as well as the reputation of the university. To achieve the performance goals of universities, it is necessary to implement the following solutions:

Building human resources not only need to do well in the recruitment stage but also need to have an appropriate mechanism, encouraging existing teaching staff to self-study and improve professional knowledge. Thereby, individuals are willing to share knowledge and create valuable scientific products. In recent years, public universities have promoted the recruitment of new staff, constantly raising the standards of recruitment, such as recruiting only personnel with a foreign doctorate or master's degree.

Schools need to build an appropriate organizational culture to encourage sharing of knowledge among faculty members. Managers need to create an open working environment, gradually eliminate gaps and barriers in communication (language, rank, income level) to promote the desire to share knowledge of trainers. . It is essential to create an organizational culture where individuals are willing to share knowledge voluntarily as well as learn, listen, and absorb others' opinions.

\subsection{Limitations and Future Improvements}

Before wrapping this study, it is crucial to acknowledge a handful of limitations that exist in this study to suggest directions for further improvements in the future. These can be listed as follows:

First, because the data provided for this research study came from a single source, namely survey respondents who are lecturers at ten local universities based in Vietnam, this might lead to the threat of common method variance (CMV), which is a serious problem for survey-based data (Podsakoff, MacKenzie, \& Podsakoff, 2012). As part of future research, gaining data from multiple sources would help to overcome the risk of CMV as suggested by Podsakoff et al. (2012). For instance, data to measure transformational leadership characteristics could be obtained from leaders of local higher education institutions in Vietnam while data to measure individual academic performance could be acquired from lecturers who are led by those leaders, this way helps us to gain multiple sources-based data. Alternatively, an in-depth interview with top leaders of several universities in Vietnam could preliminarily be conducted in order to gain insights into the status quo for implementing transformational leadership prior to carrying out the formal survey study, this qualitative interview study might serve as a pre-test to provide supplemental information that may be useful to design the survey questionnaire.

Second, although the use of non-probability sampling, by combining convenience sampling technique with referral sampling technique, could be acceptable given the natural constraints of this research, this non-probability sampling would definitely represent a major drawback in terms of the methodology due to its high sampling error that reduces the sample representativeness (Lohr, 2010). Future researchers might want to consider deploying probability sampling from their sampled framework, by investing more time and efforts in getting the full contact of all observation units in their sampled population in order to conduct the random selection process. This expects to yield a highly representative final sample.

Third, since the sample was taken from only ten private and public universities based in Ho Chi Minh City and Hanoi capital city, as the two largest cities in Vietnam, the final sample did not represent the system of more than 400 local higher education institutions, including both universities and colleges, across the country. In other words, the geographical restriction of the final sample in this study indicates another limitation that should be taken into account by future research. As part of further improvement, perhaps future samples should expand into other locations to formulate a more diverse sample that is composed of lecturers from a wider range of local institutions.

Fourth, due to the fact that this study is particularly focused on the context of the higher education sector in Vietnam, the findings derived from this work are strongly applicable to local higher education institutions but should be generalized to other populations, such as other educational settings, with a certain level of caution. To address this shortcoming, perhaps future researchers might be interested in undertaking comparative research in order to compare the transformational leadership effect on academic performance between Vietnam and another country such as Malaysia to figure out any local and situational differences. 
Finally, literature well documents that the effectiveness of leadership is context-dependent, meaning that this effect might depend on the cultural factors of the environment wherein it is examined (Davis \& Gardner, 2012). For example, Schaubroeck et al. (2007) conducted a cross-cultural study in both Hong Kong and the US and found that the effect of transformational leadership on team performance is moderated by the level of power distance and collectivism in these countries, suggesting the moderating role of national cultural factors in driving the effectiveness of transformational leadership. This current study, however, failed to include such national cultural variables (Hofstede, 2001), in the research model. Further studies therefore might want to consider the moderating role of some cultural factors, such as power distance, when examining the transformational leadership style in the higher education environment in Vietnam.

\section{References}

Abdillah, L. A. (2014). Managing information and knowledge sharing cultures in higher educations institutions. arXiv preprint arXiv:1402.4748.

Akhtar, A., Rahman, A., Husain, M., Chaudhry, I.B., Duddu, V., \& Husain, N. (2010). Multidimensional scale of perceived social support: psychometric properties in a South Asian population. Journal of Obstetrics and Gynaecology Research, $36(4), 845-851$.

Argote, L., McEvily, B., \& Reagans, R. (2003). Managing knowledge in organizations: an integrative framework and review of emerging themes. Management Science, 49(4), 571-582.

Argote, L., \& Miron-Spektor, E. (2011). Organizational learning: From experience to knowledge. Organization Science, 22(5), 1123-1137.

Argyris, C., \& Schõn, D.A. (1978). Organizational Learning: A Theory of Action Perspective. MA: Addition-Wesley.

Avolio, B.J., \& Yammarino, F.J. (2013). Transformational and Charismatic Leadership: The Road Ahead, Emerald Group Publishing, Bradford.

Bakker, A.B., \& Leiter, M.P. (2010). Work Engagement: introduction. Work Engagement: A Handbook of Essential Theory and Research. Psychology Press, Routledge.

Bass, B. M., \& Avolio, B. J. (2004). Multifactor leadership questionnaire: Manual and sample set (3rd ed.). Menlo Park, CA: Mind Garden, Inc

Bass Bernard, M. (1985), Leadership and Performance beyond Expectation. Macmillian, New York, NY.

Bass, B.M. (1999). On the taming of charisma: a reply to Janice Beyer. Leadership Quarterly, 10(4), 541-553.

Bass, B.M., \& Avolio, B.J. (1990), Transformational Leadership Development: Manual for the Multifactor Leadership Questionnaire, Consulting Psychologists Press, Palo Alto, CA.

Blau, P.M. (1964). Exchange and Power in Social Life. Transaction Publishers, New York, NY.

Bono, J., \& Judge, T. (2003). Self-concordance at work: toward understanding the motivational effects of transformational leadership. Academy of Management Journal, 46(5), 554-571.

Barro, R. J. (2001). Human capital and growth. American Economic Review, 91(2), 12-17

Boland, R. J., \& Tenkasi, R. V. (1995). Perspective making and perspective taking in communities of knowing. Organization Science, 6(4), 350-372.

Bock, G.-W., Zmud, R. W., Kim, Y.-G., \& Lee, J.-N. (2005). Behavioral intention formation in knowledge sharing: Examining the roles of extrinsic motivators, social-psychological forces, and organizational climate. MIS quarterly, 29(1), 87-111.

Burns, J.M. (1978). Leadership. Harper and Row, New York, NY.

Cabrera, A., Collins, W. C., \& Salgado, J. F. (2006). Determinants of individual engagement in knowledge sharing. The International Journal of Human Resource Management, 17(2), 245-264.

Carmeli, A., Atwater, L., \& Levi, A. (2011). How leadership enhances employees' knowledge sharing: the intervening roles of relational and organizational identification. The Journal 145 Leadership and knowledge sharing of Technology Transfer, 36(3), 257-274.

Chen, I.Y.L., Chen, N.S., \& Kinshuk (2009a). Examining the factors influencing participants' knowledge sharing behavior in virtual learning communities. Educational Technology \& Society, 12(1), 134-148.

Chen, W.L., Sandhu, M.S., \& Jain, K.K. (2009b). Knowledge sharing in an American multinational company based in Malaysia. Journal of Workplace Learning, 21(2), 125-142.

Chiu, C.M., Hsu, M.H., \& Wang, E.T. (2006). Understanding knowledge sharing in virtual communities: an integration of social capital and social cognitive theories. Decision Support Systems, 42(3), 1872-1888.

Cohen, W. M., \& Levinthal, D. A. (2000). Absorptive capacity: A new perspective on learning and innovation. Strategic Learning in a Knowledge economy (pp. 39-67): Elsevier.

Cronenwett, L.R. (1985). Parental network structure and perceived support after birth of first child. Nursing Research, $34(6), 347-351$.

Cobb, S. (1976). Social support as a moderator of life stress. Psychosomatic Medicine, 38(5), 300-314.

Cristiane, B. C., \& José Mauro da, C. H. (2019). Comparing transformational and instrumental leadership the influence of different leadership styles on individual employee and financial performance in brazilian startups: Revista de administracao e inovacao. Innovation \& Management Review, 16(2), 143-160.

Cronin, B., \& Davenport, E. (2001). Knowledge management in higher education. Information Alchemy: the art and Science of Knoledge Management,(Ed. Gerald Bernbom) EDUCASE Leadership strategies, n, 3. 
Cummings, J. N. (2004). Work Groups, Structural Diversity, and Knowledge Sharing in a Global Organization. Management Science, 50, 352-364. DOI:https://doi.org/10.1287/mnsc.1030.0134

Dari, T. A., Jabeen, F., \& Papastathopoulos, A. (2018). Examining the role of leadership inspiration, rewards and its relationship with contribution to knowledge sharing. Journal of Workplace Learning, 30(6), 488-512.

Damodaran, L., \& Olphert, W. (2000). Barriers and facilitators to the use of knowledge management systems. Behaviour \& Information Technology, 19(6), 405-413.

Del Giudice, M., Della Peruta, M. R., \& Maggioni, V. (2015). A model for the diffusion of knowledge sharing technologies inside private transport companies. Journal of Knowledge Management, 19(3), 611-625.

De Vries, R. E., Van den Hooff, B., \& de Ridder, J. A. (2006). Explaining knowledge sharing: The role of team communication styles, job satisfaction, and performance beliefs. Communication Research, 33(2), 115-135.

Dixon, N. M. (2000). Common knowledge: How companies thrive by sharing what they know: Harvard Business School Press.

Dvir, T., Eden, D., Avolio, B., \& Shamir, B. (2002). Impact of transformational leadership on follower development and performance: a field experiment. Academy of Management Journal, 45(4), 735-744,

Daft, R. L., \& Weick, K. E. (1984). Toward a model of organizations as an interpretation system. Academy of Management Review, 9, 284-295.

Fiol, C. M., \& Lyles, M.A. (1985). Organizational learning. Academy Management Review, 10, 803-813.

Foss, N. J., Husted, K., \& Michailova, S. (2010). Governing knowledge sharing in organizations: Levels of analysis, governance mechanisms, and research directions. Journal of Management Studies, 47(3), 455- 482.

Ghobadi, S. (2015). What drives knowledge sharing in software development teams: A literature review and classification framework. Information \& Management, 52(1), 82-97.

Grassmueck, G., \& Shields, M. (2010). Does government fragmentation enhance or hinder metropolitan economic growth? Papers in Regional Science, 89(3), 641-657.

Gupta, M., \& Shaheen, M. (2017). Impact of work engagement on turnover intention: moderation by psychological capital in India. Business: Theory and Practice, 18(1), 136-143.

Gupta, M., Gupta, M., Shaheen, M., Shaheen, M., Reddy, P.K., \& Reddy, P.K. (2017). Impact of psychological capital on organizational citizenship behavior: mediation by work engagement. Journal of Management Development, 36(7), 973983.

Hall, H. (2003). Borrowed theory: applying exchange theories in information science research. Library and Information Science Research, 25(3), 287-306.

Hansen, G., \& Wernerfelt, B. (1989). Determinants of firm performance in relative importance of economic and organizational factors. Strategic Management Journal, 10(5), 399-411.

Hair, J.F., Ringle, C.M., \& Sarstedt, M. (2011). PLS-SEM: in deed a silver bullet. Journal of Marketing Theory and Practice, 19(2), 139-151.

Hair, J.F., Hult, G.T.M., Ringle, C., \& Sarstedt, M. (2013). A Primer on Partial Least Squares Structural Equation Modeling (PLS-SEM). Sage Publications Ltd, London.

Hair, J. F., Henseler, J., Dijkstra, T. K., \& Sarstedt, M. (2014). Common beliefs and reality about partial least squares: comments on Rönkkö and Evermann, Organizational Research Methods, 17(2), 182-209.

Hair, J. F., Hult, G. T. M., Ringle, C. M., \& Sarstedt, M. (2017). A Primer on Partial Least Squares Structural Equation Modeling (PLS-SEM), $2^{\text {nd }}$ ed., Sage: Thousand Oaks.

Henseler, J., Ringle, C.M., \& Sarstedt, M. (2015). A new criterion for assessing discriminant validity in variance-based structural equation modeling. Journal of the Academy of Marketing Science, 43(1), 115-135.

Henseler, J., Ringle, C.M., \& Sinkovics, R.R. (2009). The use of partial least squares path modeling in international marketing, in Sinkovics, R.R. and Ghauri, P.N. (Eds), New Challenges to International Marketing, Emerald Group Publishing Limited.

Hejazi, Y. (2006). Four basics for agricultural and natural resources education. Tehran: Pooneh.

He, H., Zhu, W., \& Zheng, X. (2014). Procedural justice and employee engagement: roles of organizational identification and moral identity centrality. Journal of Business Ethics, 122(4), 681-695.

Hinds, P. J., \& Pfeffer, J. (2003). Why organizations don't "know what they know": Cognitive and motivational factors affecting the transfer of expertise. Sharing expertise: Beyond knowledge management, 3-26.

Hansen, M. T. (2002). Knowledge networks: Explaining effective knowledge sharing in multiunit companies. Organization Science, 13(3), 232-248.

House, J.S. (1981), Work Stress and Social Support, Addison-Wesley, Reading, MA.

Trong, H., \& Ngoc, C. N. M. (2008). Analysis of research data with SPSS. Volume 1\&2, Hong Duc-Hanoi Publishing House.

Huber, G. P. (1991). Organizational learning: The contributing processes and the literatures. Organizational Science, 2, 88115

Ipe, M. (2003). Knowledge sharing in organizations: A conceptual framework. Human Resource Development Review, 2(4), 337-359.

Ishikawa, J. (2012). Transformational leadership and gatekeeping leadership: The roles of norm for maintaining consensus and shared leadership in team performance: APJM. Asia Pacific Journal of Management, 29(2), 265-283. 
Jackson, S. E., Chuang, C.-H., Harden, E. E., \& Jiang, Y. (2006). Toward developing human resource management systems for knowledge-intensive teamwork Research in personnel and human resources management (pp. 27-70): Emerald Group Publishing Limited.

Judge, T.A., \& Piccolo, R.F. (2004). Transformational and transactional leadership: a meta-analytic test of their relative validity. Journal of Applied Psychology, 89(5), 755-768.

Kahn, R.L., \& Antonucci, T.C. (1980). Convoys over the life course: attachment, roles, and social support. Life-Span Development and Behavior, 13, 253-286.

Keller RT. (2012). Predicting the performance and innovativeness of scientists and engineers. Journal applied psychology, 97(1), 225-33.

Keller, R.T. (2001). Cross-functional project groups in research and new product Development: Diversity, communications, job stress, and outcomes. Academy of Management Journal, 44, 547-555.

Krueger, A. B., \& Lindahl, M. (2001). Education for growth: Why and for whom?. Journal of Economic Literature, 39(4), 1101-1136.

Kwahk, K.-Y., \& Park, D.-H. (2016). The effects of network sharing on knowledge-sharing activities and job performance in enterprise social media environments. Computers in Human Behavior, 55, 826-839.

Kassim, A. L., Raman, A., Don, Y., Daud, Y., \& Omar, M. S. (2015). The association between attitude towards the implementation of staff development training and the practice of knowledge sharing among lecturers. International Education Studies, 8(12), 108.

Kline, P., \& Saunders, B. (1995). Ten Steps to a Learning Organization: It's good for business and it's right to do. Executive Excellence, 12, 20-20.

Kothuri, S. (2002). Knowledge in Organisations. Retrieved DATE, from gseweb. harvard. edu.

Lin, H.F., \& Lee, G.G. (2004). Perceptions of senior managers toward knowledge-sharing behaviors. Management Decision, 42(1), 108-125. available at: http://dx.doi.org/ 10.1108/00251740410510181

Ling, T. N., San, L. Y., \& Hock, N. T. (2009). Trust: facilitator of knowledge- sharing culture. Communications of the IBIMA, 7(15), 137-142.

Lomi, A., Snijders, T., Steglich, C., \& Torló, V. (2011). Why are some more peer than others? Evidence from a longitudinal study of social networks and individual academic performance. Social science research, 40(6), 1506-1520.

Lyles, M. A., \& Salk, J. (1997). Knowledge acquisition from foreign partners in international joint ventures: An empirical examination in the Hungarian context. In P. Beamish \& P. Killing (Eds.), Cooperative strategies: European perspectives. San Francisco: New Lexington Press.

Lohr, S. L. (2010). Sampling: Design and Analysis (2 ${ }^{\text {nd }}$ ed.). Boston: Cengage Learning.

Macey, W.H., \& Schneider, B. (2008). Engaged in engagement: we are delighted we did it. Industrial and Organizational Psychology, 1(1), 76-83.

Manafi, M., \& Subramaniam, I. D. (2015). The role of the perceived justice in the relationship between human resource management practices and knowledge sharing: A study of Malaysian universities lecturers. Asian Social Science, 11(12), 131.

Mhatre, K.H., \& Riggio, R.E. (2014). Charismatic and transformational leadership: past, present, and future. in Day, D.V. (Ed.), The Oxford Handbook of Leadership and Organizations, Oxford University Press, New York, NY, pp. $221-240$.

Mowday, R., Porter, L., \& Steers, R. (1982). Employee-Organization Linkages: The Psychology of Commitment, Absenteeism, and Turnover. Academic Press, New York.

Meyer, J.P., Allen, N.J., \& Smith, C.A. (1993). Commitment to organizations and occupations: extension and test of a threecomponent conceptualization. Journal of Applied Psychology, 78(4), 538-546.

Mueller, J. (2014). A specific knowledge culture: cultural antecedents for knowledge sharing between project teams. European Management Journal, 32(2), 190-202. available at: http://dx.doi.org/10.1016/j.emj.2013.05.006

Nguyen Dinh Tho \& Nguyen Thi Mai Trang (2009). Scientific research in business administration: Statistics

Nguyen Dinh Tho (2011). Methods of scientific research in business. Labor - Social Publishing House, 593.

Oh, H., Chung, M. H., \& Labianca, G. (2004). Group social capital and group effectiveness: The role of informal socializing ties. Academy of Management Journal, 47(6), 860-875.

Parke, M. R., Campbell, E. M., \& Bartol, K. M. (2014). Setting the stage for virtual team development: Designing teams to foster knowledge sharing. Paper presented at the Academy of Management Proceedings.

Park, S., \& Eun-Jee, K. (2018). Fostering organizational learning through leadership and knowledge sharing. Journal of Knowledge Management, 22(6), 1408-1423. doi:http://dx.doi.org/10.1108/JKM-10-2017-0467

Podsakoff, P.M., MacKenzie, S.B., \& Bommer, W.H. (1996). Transformational leader behaviors and substitutes for leadership as determinants of employee satisfaction, commitment, trust, and organizational citizenship behaviors. Journal of Management, 22(2), 259-298, available at: http://dx.doi.org/10.1177/014920639602200204

Phong Ba, L., \& Hui, L. (2019). Determinants of innovation capability: The roles of transformational leadership, knowledge sharing and perceived organizational support. Journal of Knowledge Management, 23(3), 527-547.

Phong Ba, L., \& Hui, L. (2018). The mediating role of trust in stimulating the relationship between transformational leadership and knowledge sharing processes. Journal of Knowledge Management, 22(3), 521-537.

Reychav, I., \& Weisberg, J. (2010). Bridging intention and behavior of knowledge sharing. Journal of Knowledge Management, 14(2), pp. 285-300, available at: http://dx.doi. org/10.1108/13673271011032418

Robinson, D., Perryman, S., \& Hayday, S. (2004). The Drivers of Employee Engagement, ReportInstitute of Employment Studies. Falmer, Brighton. 
Shuck, B., \& Wollard, K. (2010). Employee engagement and HRD: a seminal review of the foundations. Human Resource Development Review, 9(1), 89-110.

Sharratt, M., \& Usoro, A. (2003). Understanding Knowledge-Sharing in Online Communities of Practice. Electronic Journal on Knowledge Management, 1, 187-196.

Shumaker, S.A., \& Brownell, A. (1984). Toward a theory of social support: closing conceptual gaps. Journal of Social Issues, 40(4), 11-36.

Sun, W., Xu, A., \& Shang, Y. (2014). Transformational leadership, team climate, and team performance within the NPD team: Evidence from china: APJM. Asia Pacific Journal of Management, 31(1), 127-147.

Van Knippenberg, D., \& Sleebos, E. (2006). Organizational identification versus organizational commitment: selfdefinition, social exchange, and job attitudes. Journal of Organizational Behavior, 27(5), 571-584.

Von Krogh, G., Ichijo, K., \& Nonaka, I. (2000). Enabling Knowledge Creation. How to Unlock the Mystery of Tacit Knowledge and Release the Power of Innovation. Oxford University Press, Inc., New York.

Vuori, V., \& Okkonen, J. (2012). Knowledge sharing motivational factors of using an intra-organizational social media platform. Journal of Knowledge Management, 16(4), 592-603.

Wang, S., \& Noe, R. A. (2010). Knowledge sharing: A review and directions for future research. Human Resource Management Review, 20(2), 115- 131.

Wang, S., \& Wang, N. (2012). Knowledge sharing, innovation and firm performance. Expert systems with applications, 39(10), 8899-8908.

Wang, W.T., \& Hou, Y.P. (2015). Motivations of employees' knowledge sharing behaviors: a selfdetermination perspective. Information and Organization, 25(1), 1-26.

Walumbwa, F. O., Avolio, B. J., \& Zhu, W. (2008). How transformational leadership weaves its influence on individual job performance: The role of identification and efficacy beliefs. Personnel Psychology, 61(4), 793-825.

Wang, G., Oh, I., Courtright, S. H., \& Colbert, A. E. (2011). Transformational leadership and performance across criteria and levels: A meta-analytic review of 25 years of research. Group \& Organization Management, 36(2), 223-270.

Wollersheim, J., Lenz, A., Welpe, I. M., \& Spörrle, M. (2015). Me, myself, and my university: A multilevel analysis of individual and institutional determinants of academic performance. Zeitschrift Für Betriebswirtschaft, 85(3), $263-291$.

Yahaya, R., \& Ebrahim, F. (2016). Leadership styles and organisational commitment: literature review. Journal of Management Development, 35(2), 190-216.

Zheng, J., Wu, G., \& Xie, H. (2017). Impacts of leadership on project-based organizational innovation performance: The mediator of knowledge sharing and moderator of social capital. Sustainability, 9(10), 1893.

\section{Appendix 1}

Personal characteristics of the participants

\begin{tabular}{|c|c|c|c|}
\hline Characteristics & Categories & Frequency & Percent \\
\hline \multirow{2}{*}{ Gender } & Male & 219 & $43.8 \%$ \\
\hline & Female & 281 & $56.2 \%$ \\
\hline \multirow{4}{*}{ Age Group } & $18-26$ years old & 113 & $22.6 \%$ \\
\hline & 27 - 32 years old & 256 & $51.2 \%$ \\
\hline & $33-40$ years old & 72 & $14.4 \%$ \\
\hline & Over 40 years old & 59 & $11.8 \%$ \\
\hline \multirow{4}{*}{ Educational Level } & Bachelor & 34 & $6.8 \%$ \\
\hline & Master & 286 & $57.2 \%$ \\
\hline & $\mathrm{PhD}$ & 149 & $29.8 \%$ \\
\hline & Associate Professor and Professor & 31 & $6.2 \%$ \\
\hline \multirow{5}{*}{ Work Experience } & $1-3$ years & 60 & $12.0 \%$ \\
\hline & $3-5$ years & 201 & $40.2 \%$ \\
\hline & $5-7$ years & 153 & $30.6 \%$ \\
\hline & $7-9$ years & 54 & $10.8 \%$ \\
\hline & More than 9 years & 32 & $6.4 \%$ \\
\hline \multirow{3}{*}{ Monthly Salary } & Below 10 million VND & 62 & $12.4 \%$ \\
\hline & 10-20 million VND & 355 & $71.0 \%$ \\
\hline & Over 20 million VND & 83 & $16.6 \%$ \\
\hline
\end{tabular}

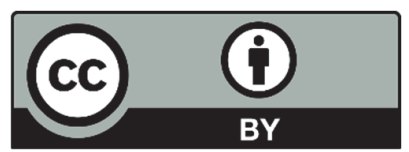

(C) 2021 by the authors; licensee Growing Science, Canada. This is an open access article distributed under the terms and conditions of the Creative Commons Attribution (CC-BY) license (http://creativecommons.org/licenses/by/4.0/). 